\title{
THE INFLUENCE OF AROMA COMPOUNDS ON SENZORIAL TRAITS OF WINES FROM THE APOLD DEPRESSION
}

\author{
Ecaterina, LENGYEL ${ }^{1}$ and László SIKOLYA ${ }^{2}$ \\ 1"Lucian Blaga" University of Sibiu, Sibiu, Romania, ecaterina.lengyel@ulbsibiu.ro \\ ${ }^{2}$ University College of Nyíregyháza, Hungary, sikolya @nyf.hu
}

\begin{abstract}
The present study aims at investigating aroma compounds in three wine varietals (Pinot gris, Traminer roz, Riesling) from Apold, the county of Sibiu, production of 2014, and their importance in realizing the sensorial profile of wines. Thus, it is ascertained that Traminer roz contains the highest amount of esters $-583.846 \mathrm{mg} / \mathrm{L}$, a value that leads to the sensorial identification of floral and fruity notes. Higher alcohols determined through chromatography imprint specific traits to Pinot gris wines: bittersweet, floral notes validated through the determined amount $(479.449 \mathrm{mg} / \mathrm{L})$. Another wine trait is the concentration of higher fatty acids which reach an amount of $252.667 \mathrm{mg} / \mathrm{L}$ in Riesling wines, conferring distinctive floral notes. The concentration of aldehydes reaches $38 \mathrm{mg} / \mathrm{L}$ in Pinot gris wine, $32.996 \mathrm{mg} / \mathrm{L}$ in Traminer roz wine; these balanced, low values do not have a negative influence on sensorial traits of these wines. Terpenes compounds are represented by nerol and $\alpha$-terpineol, whose values confer rose, lemon verbena and fruity notes, especially in the case of Traminer roz.
\end{abstract}

KEYWORDS: aromas, white wines, chromatographic methods, sensorial traits

\section{INTRODUCTION}

White wines contain hundrozs, even thousands of aroma compounds: many of them cannot be detected through classic methods, but they contribute to the formation of the sensorial qualities of wine. Scientific literature records a range of factors that lead to the formation of these aromas, starting from grape variety, climatic conditions, soil configuration, but also ever more complex must fermenting technologies, so that the amount of useful compounds getting into wine is as high as possible. More and more studies aim at improving technologies with a view to produce high quality, harmonious wines, with certain prozominant aromas, but which also retain traits specific to the soil and the region. An important factor in validating this aim is to use selected yeast cultures which are capable to potentiate as many aroma compounds as possible; in order to preserve typicity, it is recommended to isolate yeasts from the micro biota in the region. Proteolytic or glycosidic enzymes should not be excluded, as they play a well-defined role in technological wine production stages. Aroma compounds in wines can be classified as esters, higher alcohols, volatile fatty acids, aldehydes, terpene compounds, sulfur compounds, carbonyl or phenolic compounds (etc.). Esters are formed through enzymatic esterification during must fermentation and through chemical esterification during the wine maturation and aging process. Both mechanisms may underlie the formation of the same ester. During the must alcoholic fermentation, a high amount of ester forms and esterification reactions depend on technological conditions and the yeasts involved. These yeasts produce fatty acids ethyl esters, especially those in caproic and caprylic acids, which confer nice fruity aromas of apple, pineapple, and citrus. Ethyl phenylacetate plays a role in the formation of wine aromas with mild honey notes, and ethyl coumaryl-tartrate confers fruit notes. Hydroxybenzoic and hydroxy phenol acids play a part in the formation of wine aroma, even though they are not odoriferous, but, through esterification with wine alcohols, they make up aroma compounds, such as methyl and ethyl vanilla, methyl cinnamate- (Methyl trans-3-phenyl propanoate), conferring nice vanilla aromas. Many compounds are formed from precursors of subsequent reactions, like ethyl cinnamate whose precursor is ferulic acid and which imprints wines with fruity aromas and sensations. Thiols and their compounds imprint aroma notes that range from herbaceous to fruity, with notes of green pepper, flowers or grapefruit (Lund et al., 2009b). Of these, 3-marcapto-1-hexanol acetate has a complex grapefruit smell, with a perception threshold of $4 \mathrm{ng} / \mathrm{L}$, (MateoVivaracho et al., 2010, Herbst-Johnstone et al., 2011). Terpene compounds can be found in grapes, must and wine, both freely and combined, especially as glycosides, which are precursors of aromas. Terpene compounds can be found under various forms: as aldehydes (linalal, geranial), alcohols (linanool, geraniol), acids (linalic acid, geranic acid) or esters (linanyl acetate). Most noticeable monoterpenes are monoterpene alcohols, nerol, geraniol, citronellol, linalool and $\alpha$-terpineol. It can be found in grapes in lower concentrations, it has a high perception threshold, emanating a nice cantaloupe smell. Nerol has a nice plum, rose, lemon verbena smell (Wüst, 2003; Târdea, 2007). Chemical reactions of nerol resemble those of geraniol, as they are cis-trans isomers with the same structure. Both compounds are found in grape skin (Strauss et al., 1986), but nerol is cyclized faster than geraniol, becoming $\alpha$-terpineol - only higher concentrations can be detected (Wüst, 2003). Volatile compounds in glycosides can be released through 
several reactions with acids, leading to their transformation in monoterpenes through enzymatic hydrolysis too, as this reaction leads to a natural enhancement of aromas in wine (Godden et al., 2005; Guerin et al., 2009). Higher alcohols are found in wines as isobutyl alcohol and isoamyl alcohol; their concentration in wine ranges between 0.10 and $0.75 \mathrm{~g} / \mathrm{l}$ (Berlanga et al., 2004). The highest proportion recorded is that of Isobutyl alcohol; its content can reach $35-50 \%$ of the total amount of higher alcohols in wine (Peinado et al., 2009; Berlanga et al., 2004; Lengyel, 2012). Important aroma alcohols are: phenyl-2-ethanol, thyrozol and tryptophol. Wine contains small amounts formed through the enzymatic degradation of some amino acids (Târdea, 2007).

\section{MATERIALS AND METHODS}

Wines: Pinot gris, Traminer roz, Riesling

Provenance: Apold vineyard, production of 2014

Methods: GC-MS; chromatographic analysis includes successive separation and analysis methods of aroma compounds in wine samples. Separation takes place before analysis and is done by repeating two-phase distribution balance several times. We used C18 chromatographic column as immobile or stationary phase, while in the case of the mobile phase - the wine sample was pre-prepares - it was moving, travelling through the gaps of the first phase. Separation takes place in the chromatographic column. The mobile phase, i.e. the eluent, causes the migration of aromatic compounds in the separated mixture along the chromatographic column at various speeds. $1 \mathrm{ml}$ of the mixture under separation is introduced with a micro syringe as solution at the beginning of the column, and part of the compounds in the sample migrate due to their washing with eluent at different speeds. The temperature of the volatile compounds injector was $150^{\circ} \mathrm{C}$. This effect is known as retention and caused the so-called differential migration, as molecules migrated in groups and each group was made up of similar molecules. The device has a physical and chemical analyzer which is sensitive to the components coming out of the column; it is placed in the eluent, at the column end. This detector can provide a result which is proportional to the concentration of the component solution in the mobile phase related to time, which results in a chromatogram on recording peaks, i.e. maximum concentrations of identified compounds. Aroma compounds are identified by comparing the resulted spectrum with the standard solution previously injected. For this determination, we used aroma compounds standards from Sigma Aldrich both for esters and for volatile fatty acids, higher alcohols, aldehydes and terpenic compounds (http://www.sigmaaldrich.com/analyticalchromatography.html).

\section{RESULTS AND DISCUSSIONS}

By analyzing the results, we can determine the accumulation of esters in wines from Apold; figure 1 showing their value.

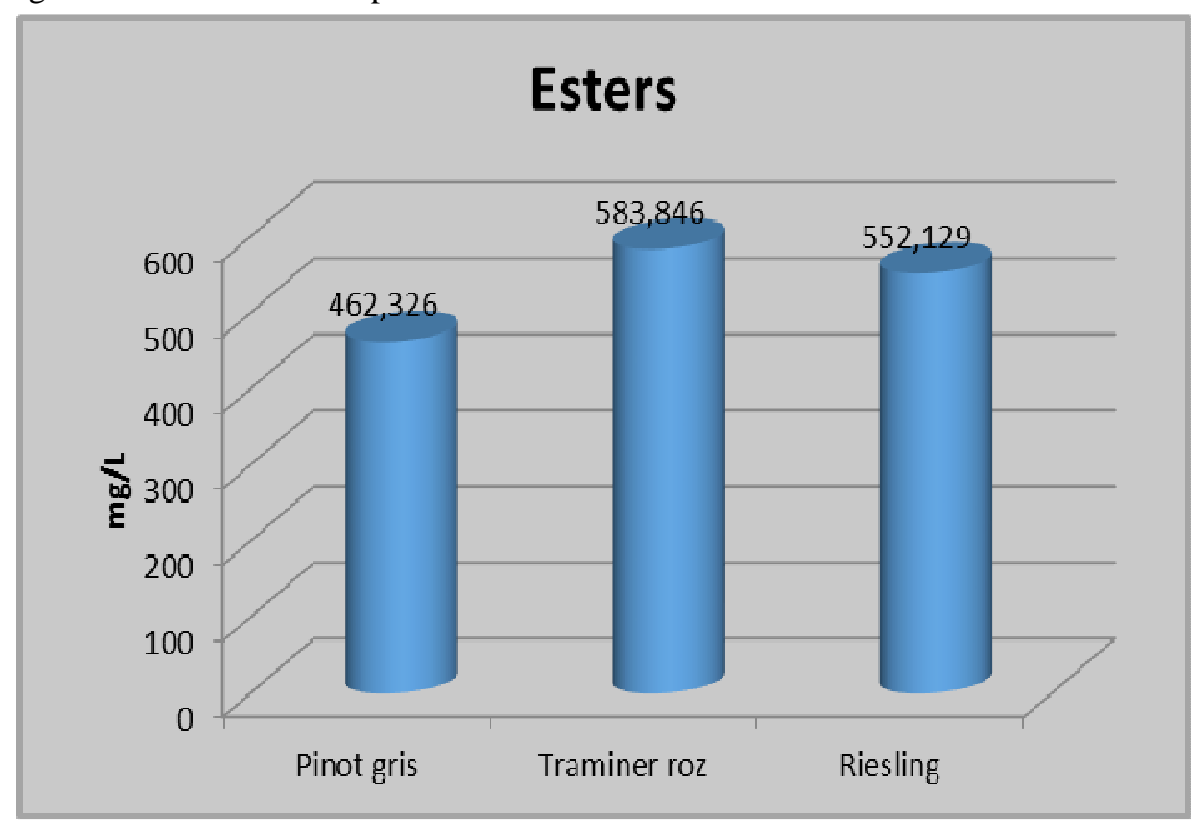

Figure 1. The evolution of esters in Pinot gris, Traminer roz and Riesling wines from Apold, harvest of 2014

We notice that Traminer roz records the highest accumulation of esters: $583.846 \mathrm{mg} / \mathrm{L}$. The amount recorded in Riesling wine is $31.717 \mathrm{mg} / \mathrm{L}$ lower, while in Pinot gris the amount of esters is $21.9 \%$ lower than in the case of Traminer roz. Another indicator used in wine characterizations is the amount of higher alcohols that leads to the formation of nice floral aromas in wine. Figure 2 shows that, in the Apold wine region and especially in the case of the wines under study, the maximum value is $479.449 \mathrm{mg} / \mathrm{L}$ in Pinot gris, followed by Riesling with $412.921 \mathrm{mg} / \mathrm{L}$. Traminer roz contains the lowest amount of higher alcohols $(373.815 \mathrm{mg} / \mathrm{L})$, but this does not downgrade the wine. Higher alcohols determined through chromatographic methods confer specific traits to wine, but their aroma also depends to a great extent on the components in the detected amount. 


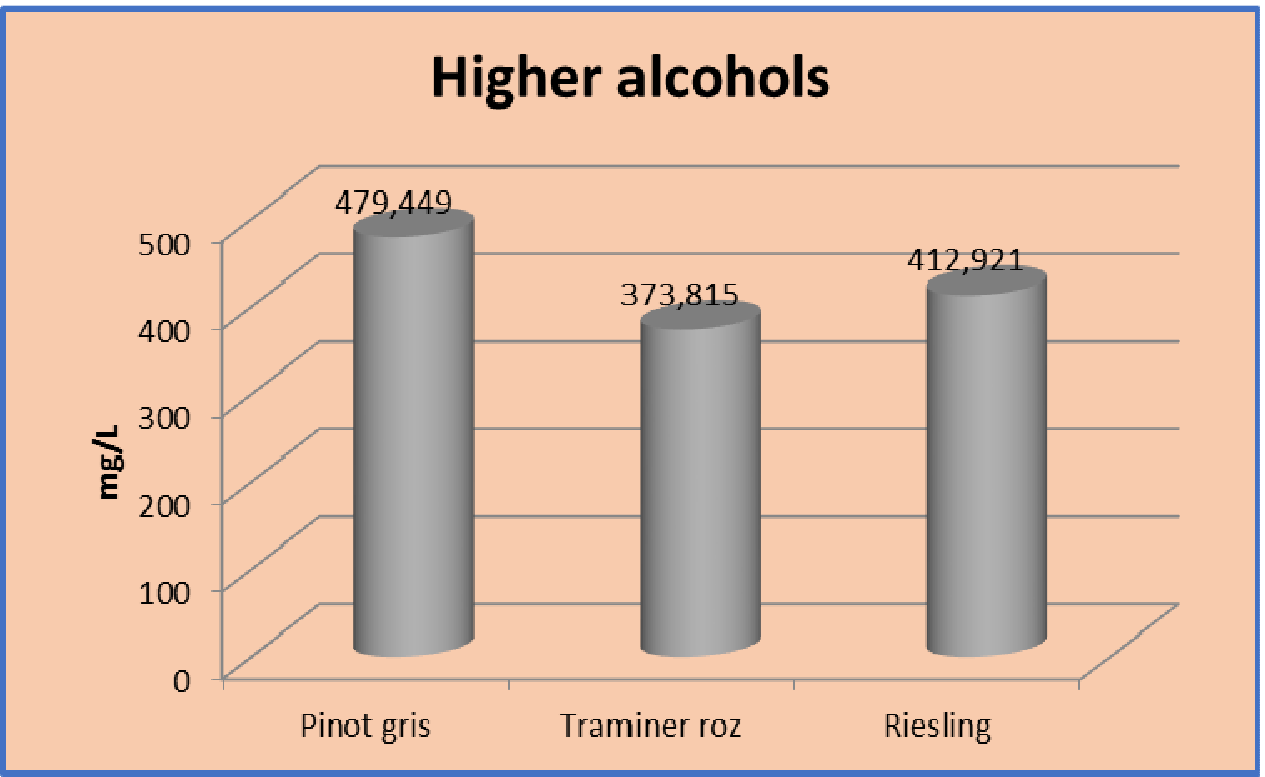

Figure 2. The evolution of higher alcohols in Pinot gris, Traminer roz and Riesling wines from Apold, harvest of 2014

Volatile fatty acids imprint floral notes to wines (valeric/pentanoic acid, caproic/hexanoic acid, caprylic/octanoic acid, lauric/dodecanoic acid) and also rancid notes through butyric acid or 2-methyl butyric. According to figure 3 , volatile fatty acids range between a minimum value of $165.555 \mathrm{mg} / \mathrm{L}$ in the case of Pinot gris and a maximum value of $252.667 \mathrm{mg} / \mathrm{L}$ in the case of Riesling. In the case of Traminer roz, we recorded a middle value of $212.006 \mathrm{mg} / \mathrm{L}$, $16 \%$ lower than the maximum value determined. In the case of Pinot gris, the highest amount of volatile fatty acids found were those of dodecanoic acid (39.234 mg/L) and octanoic acid (27.456 mg/L). In Traminer roz wines, dodecanoic acid recorded values of $32.175 \mathrm{mg} / \mathrm{L}$ and octanoic acid recorded values of $19.993 \mathrm{mg} / \mathrm{L}$. In the case of Riesling, it contains $32.341 \mathrm{mg} / \mathrm{L}$ decanoic acid and $29.443 \mathrm{mg} / \mathrm{L}$ octanoic acid. Butyric acid recorded $3.002 \mathrm{mg} / \mathrm{L}$ in Pinot gris wines, 4,109 $\mathrm{mg} / \mathrm{L}$ in Riesling wines and $1,985 \mathrm{mg} / \mathrm{L}$ in Traminer roz. 2methyl butyric acid recorded sub-unit values, as follows: 0.998 $\mathrm{mg} / \mathrm{L}$ in Pinot gris, $0.781 \mathrm{mg} / \mathrm{L}$ in Riesling and $0.663 \mathrm{mg} / \mathrm{L}$ in Traminer roz. Another volatile acid compound we found was phenylacetic acid, whose values range between $2.5 \mathrm{mg} / \mathrm{L}$ and $2.8 \mathrm{mg} / \mathrm{L}$. This acid contributed to the formation of the floral aroma of wines.

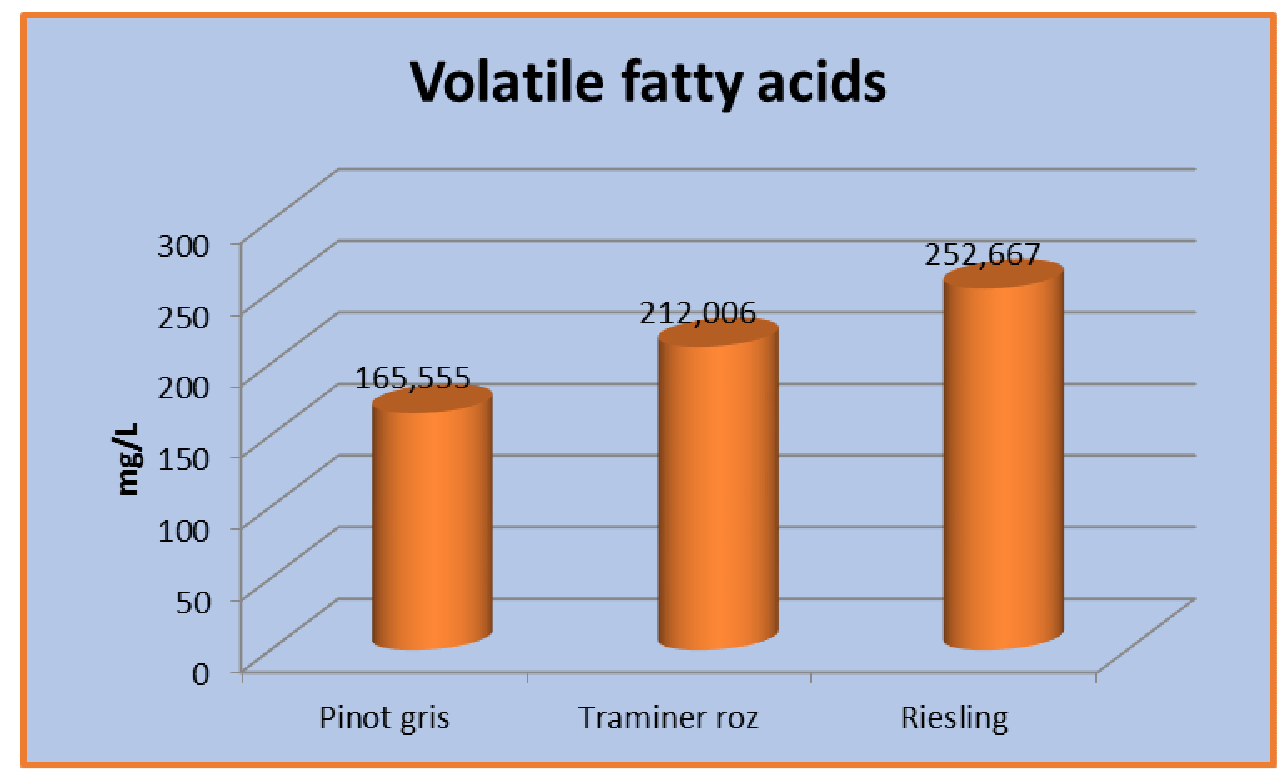

Figure 3. The evolution of volatile fatty acids in Pinot gris, Traminer roz and Riesling wines from Apold, harvest of 2014 


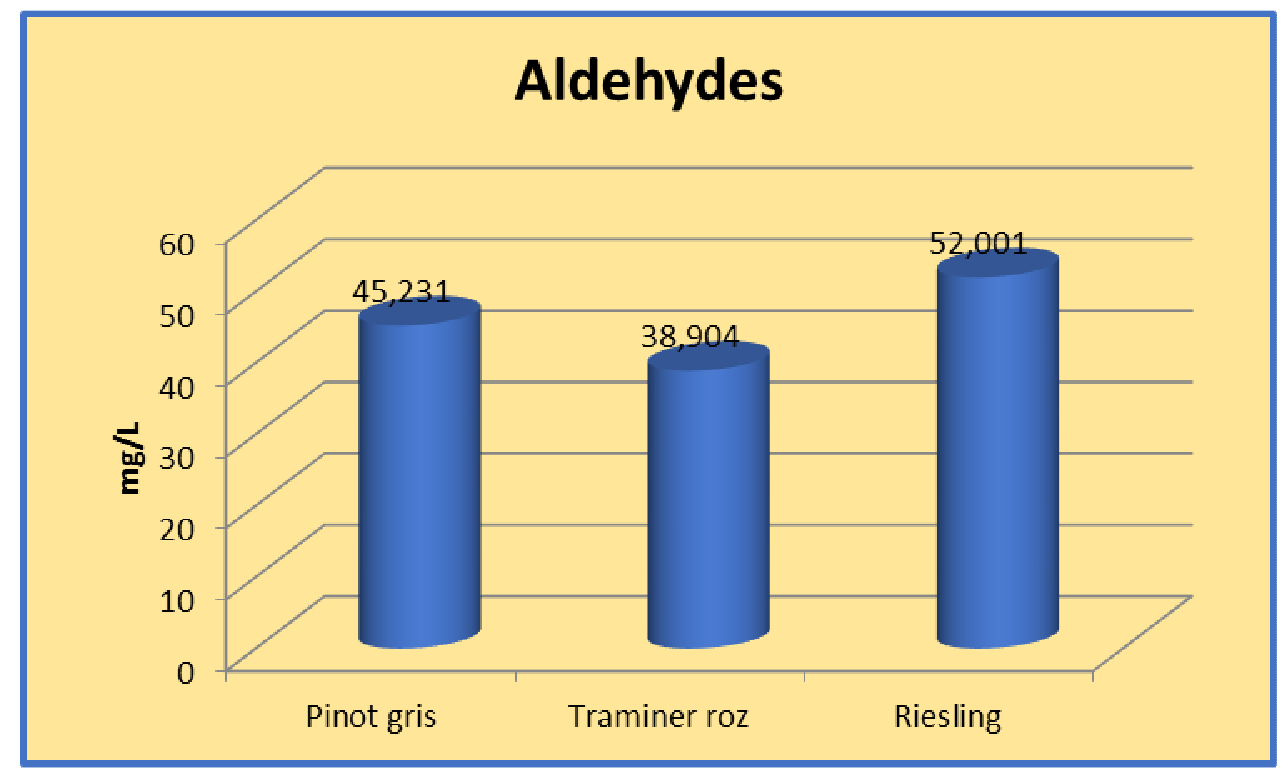

Figure 4. The evolution of aldehydes in Pinot gris, Traminer roz and Riesling wines from Apold, harvest of 2014

Aldehydes are compounds that generally form during the wine aging process, conferring sour, almond, vanilla notes, depending on their concentrations. According to figure 4, the highest amount of acetaldehyde recorded in Pinot gris was 38 $\mathrm{mg} / \mathrm{L}, 32.996 \mathrm{mg} / \mathrm{L}$ in Traminer $\mathrm{roz}$ and $47.328 \mathrm{mg} / \mathrm{L}$ in Riesling; according to scientific literature, this values are around the minimum limit. We also identified aromatic aldehydes, such as benzaldehyde and vanillin, which range between $0.233 \mathrm{mg} / \mathrm{L}$ and $0.311 \mathrm{mg} / \mathrm{L}$. Benzaldehyde imprints wines with aromatic nuances of bitter almonds, while vanillin imprints vanilla notes, as suggested by its name.
Terpenic compounds contribute to the formation of wine aromatic profile, imprinting fruity notes, such as cantaloupe and plums or floral, such as rose, lemon verbena. Their amount in wine is important exactly because they can imprint different notes which can prevail and finally lead to specificity. The values of terpene compounds obtained (figure 5) reached $1.9975 \mathrm{mg} / \mathrm{L}$ in Pinot gris, 75\% higher in Traminer roz (3.6064) and 9.7\% higher in Riesling. The most significant values were those of nerol and $\alpha$-terpineol; in the case of Pinot gris, the values recorded are $1.3873 \mathrm{mg} / \mathrm{L}$, respectively 0.3441 $\mathrm{mg} / \mathrm{L}$, in Traminer roz the values are $3.0012 \mathrm{mg} / \mathrm{L}$, respectively $0.3256 \mathrm{mg} / \mathrm{L}$ and in Riesling $1.8356 \mathrm{mg} / \mathrm{L}$, respectively 0.2111 $\mathrm{mg} / \mathrm{L}$.

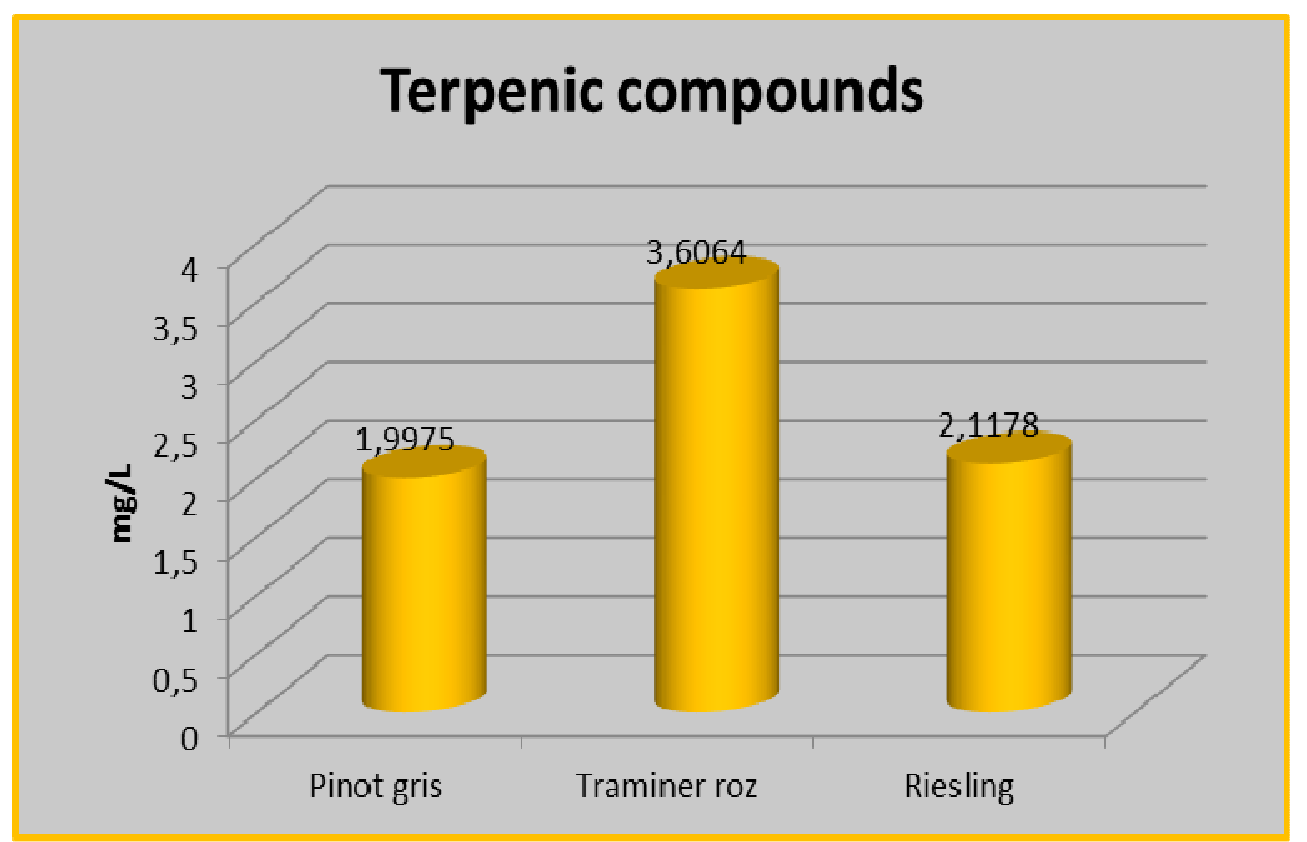

Figure 5. The evolution of terpenic compounds in Pinot gris, Traminer roz and Riesling wines from Apold, harvest of 2014

The sensorial characterization of Pinot gris, Traminer roz and Riesling wines from Apold, harvest of 2014, based on GC-MS provides an overview of the wine qualities under study. Pinot gris stands out by a lower amount of esters $(462.326 \mathrm{mg} / \mathrm{L})$, volatile fatty acids $(165.555 \mathrm{mg} / \mathrm{L})$ and a higher amount of higher alcohols (479.449 $\mathrm{mg} / \mathrm{L})$. Therefore, it has the notes of a wine with fine, full body, extractable and slightly spicy aromas, but the prozominant notes are bittersweet, resulting from the high amount of higher alcohols according to the results obtained (figure 6). 


\section{Pinot gris}

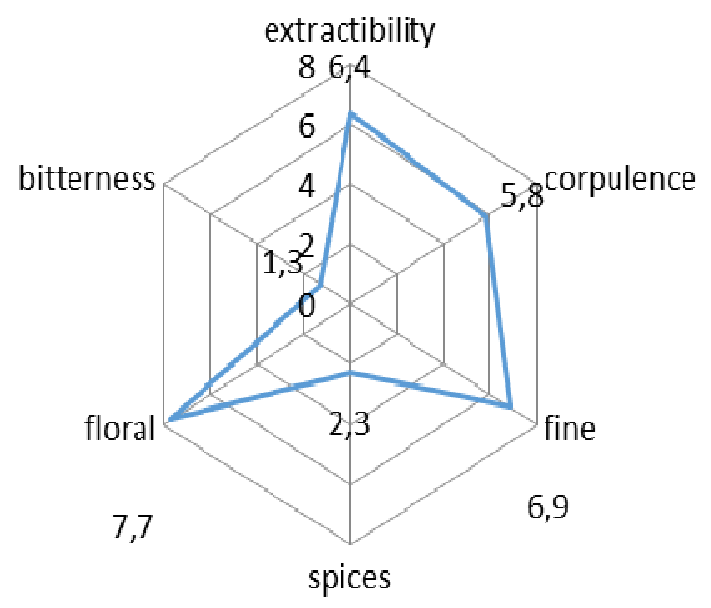

Figure 6. The sensorial profile of Pinot gris wine from Apold, harvest of 2014

Figure 7 depicts Traminer roz wines as slightly pungent, flavoroz and with pleasant rose notes (imprinted by nerol), unctuous and soft (esters and volatile fatty acids). Low amounts of aldehyde result in a balanced, harmonious wine, with pleasant inserts of spices (sulfur compounds). Riesling wine is richer in esters $(552.129 \mathrm{mg} / \mathrm{L})$, which is why it has pleasant floral aromas (conferroz by caprylic and lauric fatty acids), fruit aromas (neutral esters of fatty acids), honey and musk aromas conferroz by ethyl phenylacetate (figure 8 ).

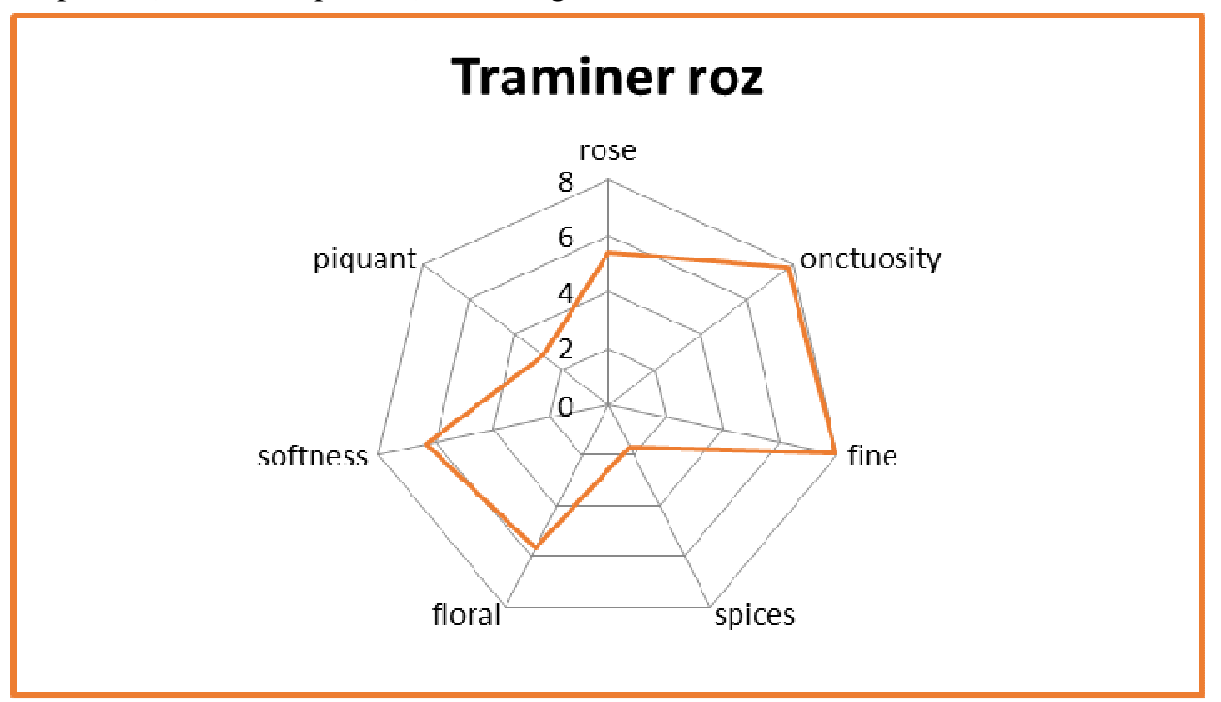

Figure 7. The sensorial profile of Traminer roz wine from Apold, harvest of 2014

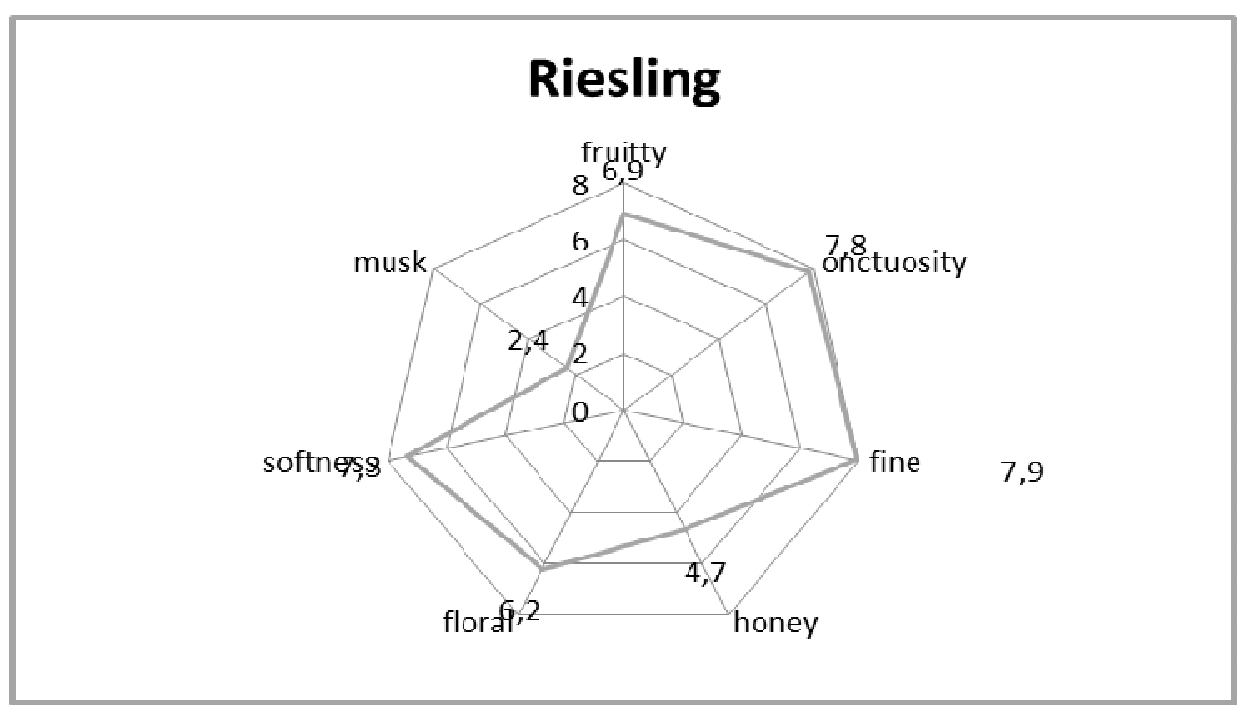

Figure 8. The sensorial profile of Riesling wine from Apold, harvest of 2014 


\section{CONCLUSIONS}

- modern GC-MS aroma compound determination methods lead to precise and rigorous results which can characterize wines from a chemical point of view

- cumulated ester values result in harmonious, aromatic, fine wines, with significant differences firstly caused by variety

- depending on these values, wines show distinct flower, fruit or honey aromas, as is the case of Riesling

- the amount of volatile alcohols leads to the formation of vegetal, floral or rose aromas, especially in the case of Traminer roz

- the amount of volatile fatty acids determined in the three wines from Apold, harvest of 2014 - Pinot gris, Traminer roz and Riesling - imprint wines with floral, gentle traits

- from a senzorial point of view, wines stand out by the fact that the aromas felt through wine tasting combine with the chemical results obtained and can be explained according to their concentration in the three varietals (Pinot gris, Traminer roz and Riesling).

\section{ACKNOWLEDGMENT}

This work was supported by the strategic grant POSDRU/159/1.5/S/133255, Project ID 133255 (2014), cofinanced by the European Social Fund within the Sectorial Operational Program Human Resources Development 20072013

\section{REFERENCES}

1. Berlanga, M. T., Peinado, R., Millan, C., Mauricio, J. C., and Ortega, J. M. (2004). Influence of blending on the content of different compounds in the biological aging of sherry dry wines. J. Agric. Food Chem.52, 2577-2581

2. Godden, P.,W., Gishen, M., 2005, Trends in the composition of Australian wine 1984-2004. In: Blair R.J., Francis M.E., and Pretorius I.S., (ed) Advances in wine science-commemorating 50 years of The Australian Wine
Research Institute, The Australian Wine Research Industrie, 115-139

3. Guerin-Schneider, R., 2009, Los compuestos volátiles nos on todos perjudiciales!, Seminario Téchnico Compuestos azufrados volatiles en vinos Problemas de rozucción y aromas varietales, 36-40

4. Herbst-Johnstone, M., Nicolau, L., and Kilmartin, P.,A., 2011, Stability of varietal thiols in commercial Sauvignon blanc wines, American Journal of Enology and Viticulture, 62, 495-502

5. Lengyel, E., Primary aromatic character of wines, Acta Universitatis Cibiniensis, Series E: Food Technology, vol.XVI, (1), 3-18, 2012

6. Lund, C.M., Thompson, M.K., Benkwitz, F., Wohler, M.W., Triggs, C.M., Gardner, R., Heymann, H. and Nicolau, L., 2009b, New Zealand Sauvignon blanc distinct flavor characteristics: Sensory, chemical, and consumer aspects. American Journal of Enology and Viticulture 60, $1-12$

7. Mateo-Vivaracho, L., Zapata, J., Cacho, J. and Ferreira, V., 2010, Analysis, occurrence, and potential sensory significance of five polyfunctional mercaptans in white wines. Journal of Agricultural and Food Chemistry 58, 10184-10194

8. Peinado, R. and Mauricio, J. (2009). Biologically aged wines.In"Wine Chemistry and Biochemistry Au17', (M. C. Polo and M. V. Moreno-Arribas, Eds), pp. 81-101. Springer LifeSciences Publisher

9. Strauss, C.R., Wilson, Gooley, P.R. and Williams, P.J., 1986, Role of Monoterpenes in Grape and Wine Flavor. Reprinted Symposium Series No 317, Biogenerations of Aromas

10. Țârdea, C.,2007, Chimia și analiza vinului, Ed. Ion Ionescu de la Brad

11. Wüst, M., 2003, Zur Biochemie des sortentypischen Weinaromas, Chem.Unserer Zeit 1/37, 8-17 